\title{
A PR̈OCESS FOR SEPARATING ACID-SUGAR MIXTURES USING ION EXCLUSION CHROMATOGRAPHY
}

\author{
R. D. Hester and S. W. Hartfield \\ University of Southern Mississippi \\ Hattiesburg, Mississippi
}

G. E. Farina

Tennessee Valley Authority

Muscle Shoals, Alabama

\begin{abstract}
Work conducted at the Tennessee Valley Authority (TVA) using a low-temperature concentrated sulfuric acid hydrolysis process to convert the cellulosic fraction of corn stover to monomeric sugars demonstrated the high conversion efficiencies possible with that process. The TVA work also confirmed the need for a cost-effective acid-sugar separation process. With the Polymer Science Department of The University of Southern Mississippi (USM), a preparative-scale ion-exclusion chromatography (IEC) system was designed, constructed, and tested with a variety of synthetic solutions and actual hydrolyzates. Although significant dispersion was observed initially, design changes were effective in minimizing this phenomenon. Data collected during the operation of the preparative-scale system were used in the design and construction of an IEC miniplant capable of processing larger volumes of synthetic solutions or hydrolyzates and in the design of an extraction-assisted IEC system. The data were also used to assess the viability of a continuous feed IEC system. This paper includes a discussion of the IEC process, provides overall material balances for various IEC process scenarios, and presents a discussion on process economics.
\end{abstract}

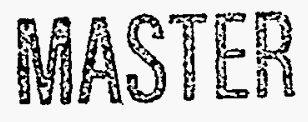




\section{DISCLAIMER}

This report was prepared as an account of work sponsored by an agency of the United States Government. Neither the United States Government nor any agency thereof, nor any of their employees, make any warranty, express or implied, or assumes any legal liability or responsibility for the accuracy, completeness, or usefulness of any information, apparatus, product, or process disclosed, or represents that its use would not infringe privately owned rights. Reference herein to any specific commercial product, process, or service by trade name, trademark, manufacturer, or otherwise does not necessarily constitute or imply its endorsement, recommendation, or favoring by the United States Government or any agency thereof. The views and opinions of authors expressed herein do not necessarily state or reflect those of the United States Government or any agency thereof. 


\section{DISCLAIMER}

Portions of this document may be illegible in electronic image products. Images are produced from the best available original document. 


\section{Introduction}

With the support of the United States Department of Energy (DOE), the Tennessee Valley Authority (TVA) began a program to assess the possibility of converting agricultural residues to fermentable sugars using a concentraled acid hydrolysis process. An experimental plant, designed to process 4 tons per day of corn stover was constructed and operated at TVA's Environmental Research Center in Muscle Shoals, Alabama, in 1984 (Farina et al. 1988). The process selected used lime to precipitate the sulfuric acid as gypsum.

The work demonsirated the excellent hemicellulose and cellulose conversion efficiencies of the concentrated acid process. However, because of the high cost associaled with the acid neutralization step, the process was economically unattractive. Therefore, it was decided to investigated teclunology options for separating and recycling the acid used in the process.

The performance of ion-exclusion chromatograpliy (IEC) columns to treat both organic and inorganic mixtures with several different resins was evaluated in 1953 by Wheaton and Bauman with both organic and inorganic mixlures. Additonal work (Wheaton and Bauman 1953) demonstraled the ability of IEC systems to effectively separate large non-ionic species, such as sugars, which had been reported to be inseparable. Work conducled at the Laboratory of Renewable Resources Engineering (Newman et al. 1987) verified the potential of using IEC columns to effectively separate sulfuric acid from glucose in aqueous solutions. The researchers noted, however, the potential for significant dispersion (a broadening and flallening of the elution profiles) for such systems.

A literature review was conducted and an equilibrium IEC model was generated (Nanguneri 1990). The IEC model was developed from one originally designed and tested for a sodium chloride/glycerol system. The model predicted the dimensionless concentration of a species in an eluent leaving a column as a function of dimensionless time. The data published by Neuman et al. were then matched to the model to predict a height equivalent to a theoretical plate for both acid and sugar.

The data collected were used to develop a spreadsheet to predict the cost associated with a commercial-scale IEC system. These costs were then compared to the acid neutralization system. It was found that a conventional batch IEC system could operate at approximately $55 \%$ of the cost of the acid neutralization system.

Based on the results of this work, a preparativescale IEC system was designed and constructed (Nanguneri 1991). Operation of the preparalivescale system confirmed the dispersion noted in previous work. Although dispersion caused by large feed volumes, high flux rates, and acid concentrations is inherent in all IEC closed-bed sy'stems, it was discovered that a significant amount of the dispersion was due to formation of a dilution layer resulting from shrinkage of the resin bed caused by high acid concentrations. A floating distribution plate was designed to eliminate the dilution layer. The success of this work lead to the design and construction of an IEC miniplant capable of processing $50 \mathrm{lb} / \mathrm{day}$ of hydrolyzate or synthetic solution. The 2-indiameler, 10-ft-long column was designed with fixed distribution plates. By employing countergravity flow, it was possible to achieve similar performance in the miniplant column as that achieved in the much smaller preparative-scale column.

Mathemalical prediclions for simulated moving bed systems employing floating and fixed distribution plates, as well as a novel extractionassisted ion-exclusion chromatography (EAIEC) system, were made to assess the theoretical pcrform ance of these systems with respect to the batch feed systems lested. With this dala, it was then possible to predict the relative economic performance of each system. 


\section{Discussion}

\section{Performance Anylysis for Batch Feed IEC Systems}

The performance of batch feed IEC systems is accomplished with ${ }^{3}$ the use of chromatograms such as shown in Figure 1.

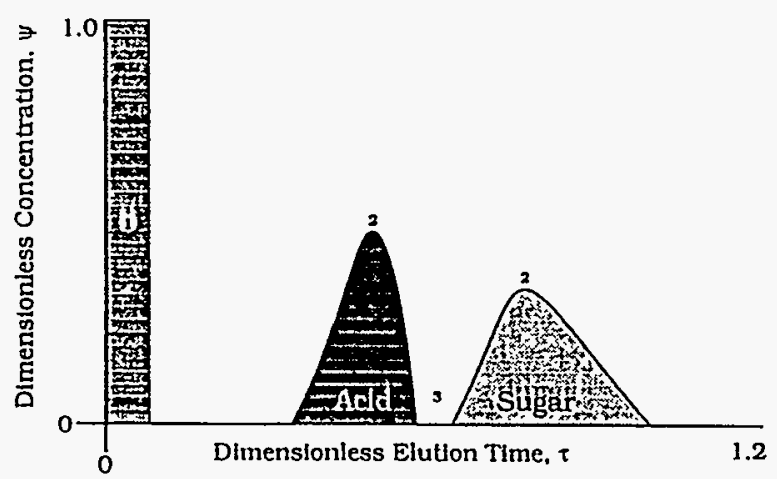

Figure 1. Typical elution profile for batch feed IEC

Chromatograms are plots of dimensionless spccies concentration, $\Psi$, versus dimensionless time, $\tau$. Dimensionless concentration is defined to be $\Psi=\mathrm{C}_{\mathrm{e}} / \mathrm{C}_{\mathrm{r}}$ and dimensionless concentration is defined to be

$$
\tau=Q t /[(\alpha+\beta) \phi S L]
$$

where:

$\mathrm{C}_{e}=$ species concentration in the eluent, $\mathrm{C}_{\mathrm{f}}=$ species concentration in the feed,

$Q=$ volumetric flow rate,

$t=$ time elapsed from start of feed,

$\alpha=$ macropore volume fraction,

$\beta=$ micropore volume fraction,

$\phi=$ column volume correction for redistribution and feed plate volumes,

$S=$ column cross sectional area,

$\mathrm{L}=$ column length.

In Figure 1, area 1 corresponds to the volume of each species injected by mass balance, the arca under each curve 2; therefore, it must be equal to area 1. Enhanced IEC performance would be identified with large injection feed quantities 1 , narrow species elution distributions 2 with large peak heights, and minimized overlap or gap 3 between the species.

\section{Preparative-Scale IEC System}

A preparative-scale IEC system consisting of three 2-in-diameter, 4-ft-long glass columns was constructed and tested (Nanguneri 1991) to evaluate several design parameters that affect the performance of IEC columns including:

1. the total amount of acid injected in a feed volume of hydrolyzate,

2. the fluid flux rate through the column,

3. the resin crosslink density

4. the column length.

The resins tested in the preparative-scale IEC system were packed in the columns in accordance with resin manufactures recommendations. It was noted in the evaluation of the preparative-scale system that increased acid loadings resulted in a dead volume, caused by a shrinkage of resin above the resin bed. This dead volume exacerbated the dispersion norm ally associated with increased acid loadings, high feed volumes, and high flux rates. To minimize the dispersion observed, a floating distribution plate was design and employed in the system. The distribution plate resulted in improved performance of the preparative-scale IEC system.

Of the resins evaluated in the preparative-scale tests, the IR $118 \mathrm{H}^{+}$(Rohm and Haas) with $4.5 \%$ crosslinking proved to be the most effective. This level of crosslinking gave a resin with high micropore volume with relatively low shrinkage.

IEC Miniplant

A second generation system having a much larger column and incorporating features necessary for automated control was design and 
constructed at the Polymer Science Department of The University of Southern Mississippi. Figure 2 is a schematic of the miniplant.

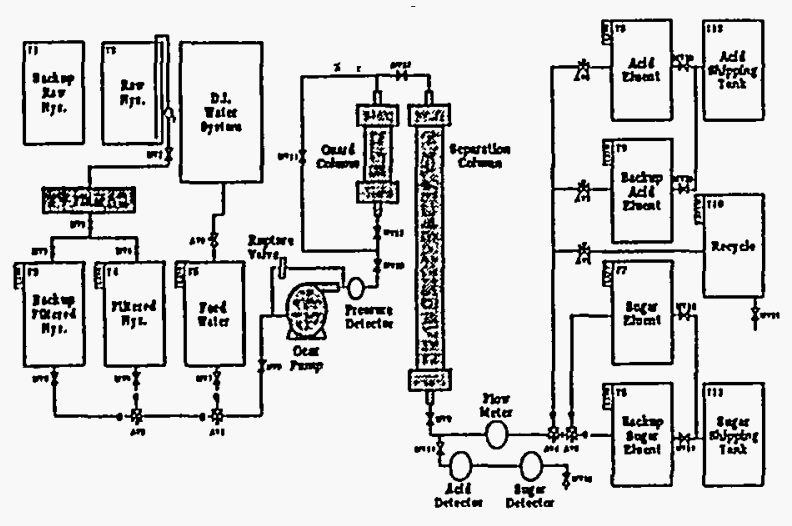

Figure 2. IEC miniplant

The minipant, which uses a single 2-in-diameter, 10 -ft-long column to process $50 \mathrm{lb} /$ day of hydrolyzate, was design to evaluate the feasibility of a commercial-scale batch feed IEC system. A Camile process controller, purchased from Dow Chemical Company, was used in the miniplant design. Control sequences for the Camile unit were written for the process pump, directional valves, and water purification system. The Camile unit was also used to monitor tank levels and to record data from the inline detectors. The miniplant column, which was constructed of schedule $80 \mathrm{CPVC}$ pipe, was filted with five fixed redistribution plates.

The original pump purchased for the miniplant, which was constructed of Hasteloy B-2, was corroded by the hydrolyzate used in the test series within 50 hours. Based on observations of the pump body, which showed corrosion limited to areas adjacent to the pump gears, and tests of the material, it was concluded that the speed of the the gears reseulted in high fluid turbulence around those areas and prevented formation of a protective oxide film. A replacement pump constructed of glass-filled Ryton polymer perforned satisfactory during the test series.

The acid detector used in the miniplant was a fully automated Kyoto model CM-117 conductivity meter. The sugar detector used was a JASCO model DIP-370 digital polarimeter which measures optical rotation. Table 1 shows typical mass flow rates for the miniplant.

Table 1. Miniplant Flow Rates

\begin{tabular}{|c|c|c|c|}
\hline \multicolumn{2}{|c|}{ STREAM } & \multirow[t]{2}{*}{ COMPONENTS } & \multirow[t]{2}{*}{ TIRUUGIIPUT } \\
\hline No. & Descatplon & & \\
\hline \multirow[t]{5}{*}{ SI } & \multirow[t]{5}{*}{ Hydrolyzate } & Sugars (ib/ht) & 0.174 \\
\hline & & Sulfuric Acid $(\mathrm{lb} / \mathrm{hr})$ & 0.327 \\
\hline & & Waler (lh/hr) & 1.677 \\
\hline & & Total (lb/hs) & 2.178 \\
\hline & & Tolal $(\mathrm{ga} / \mathrm{h} / \mathrm{r})$ & 0.261 \\
\hline \multirow[t]{3}{*}{$\$ 2$} & \multirow[t]{3}{*}{ Feed Waler } & Water (lb/hr) & 6.797 \\
\hline & & Tolal (lb/hr) & 6.797 \\
\hline & & Total $(\mathrm{gal} / \mathrm{hr})$ & 0.814 \\
\hline \multirow[t]{5}{*}{$\$ 3$} & \multirow[t]{5}{*}{ Sugar Eluent } & Sugars (1b/hr) & 0.174 \\
\hline & & Sulluric Acld (lb/hr) & 1000 \\
\hline & & Waler $(\mathrm{lb} / \mathrm{hr})$ & 5.932 \\
\hline & & Tolal (lb/hl $)$ & 6.106 \\
\hline & & Total (gal/ht) & 0.731 \\
\hline \multirow[t]{5}{*}{$\overline{\$ 4}$} & \multirow[t]{5}{*}{ Acid Eluent } & Sugars $(\mathrm{b} / \mathrm{hr})$ & $\overline{O G M}$ \\
\hline & & Acid $(1 \mathrm{~b} / \mathrm{hr})$ & 0.327 \\
\hline & & Water (ib/hs) & 2.545 \\
\hline & & Total $(\mathrm{Ib} / \mathrm{ht})$ & 2.869 \\
\hline & & Total (gai/hr) & $\overline{0.344}$ \\
\hline
\end{tabular}

Countergravity flow through the miniplant column was used during the test series. The countergravity flow and the presence of the redistribution plates minimized dispersion in the system. Performance of the miniplant was commensurate with the preparative-scale IEC system tested. Figure 3 shows a comparison of the performance of the miniplant and the preparative-scale IEC columns.

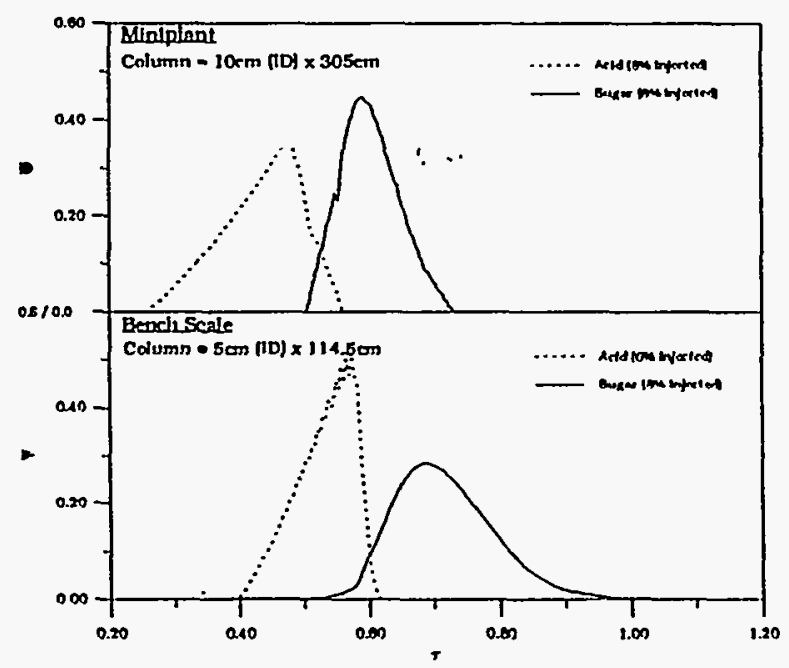

Figure 3. Comparison of miniplant and preparative-scale IEC columns

(Feed volume $=5 \%$. Flux rate $=0.66 \mathrm{~cm} / \mathrm{min}$ ) 


\section{Continuous Feed IEC System}

The dispersion minimization techniques developed for the batch feed IEC systems would also be beneficial for a continuous feed IEC system. Continuous chromatography systems have been studied in some detail (Wankat 1986). Countercurrent bed flow is a technique designed to improve the efficiency of a batch feed system by moving the solid resin countercurrent to the fluid flow direction. Countercurrent bed flow can be accomplished by fixing the resin and simulating its motion by switching fluid flow patterns to the columns containing the resin. This technique was first used in 1841 (Treybal 1980). Today it is used for leaching and has been applied to adsorption and ion exchange chromatography (King 1980, Kunin 1972, Streat 1980). Shown in Figure 4 is the fluid flow pattern for a five-column continuous feed IEC system. In the system, process valves are sequenced to change the flow patterns to and from the five columns. For example, in time slice one, feed is continuous to column three while the acid and sugar rich streams exit columns five and one, respectively. In time slice two, flow is redirected so that feed is to column four and the acid and sugar rich streams elute from columns one and two respectively.
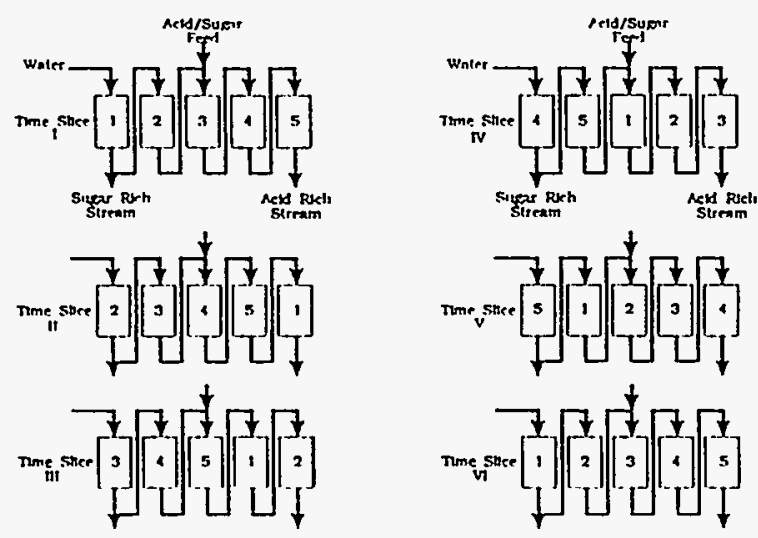

Figure 4. Continuous IEC system design

Since no tests were conducted using a continuous IEC system, it was necessary to design a mathematical model to predict its performance. The mathem atical model developed for the batch feed IEC system, which was based on the concept of a theoretical plate where species concentrations throughout the column were predicted as a function of time by performing a plate-to-plate calculation, was modified for the continuous system. For this model, the set of columns used for simulated bed movement was viewed as one large column in which the feed stream enters someplace near the middle, the water enters the top, the acid stream is taken off at the bottom, and the sugar stream is taken off near the top. The mathematical conception of the continuous IEC system is shown in Figure 5.

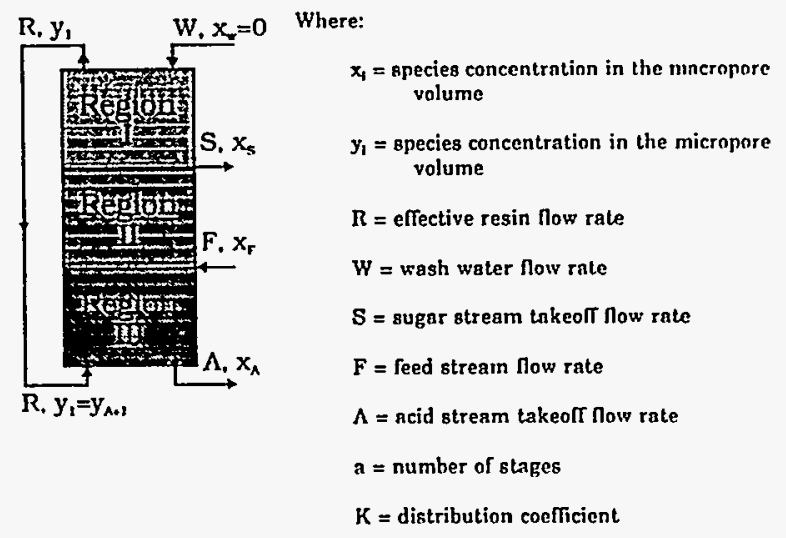

\section{Figure 5. Mathematical model of a continuous IEC system}

Based on model predictions, a continuous IEC system is capable of appreciably lowering the resin and water requirements for the IEC system. The simulated moving bed IEC system might reduce water consumption by $70 \%$ and resin requirements by as much as $90 \%$.

\section{Extraction-Assisted IEC}

Extraclion-assisted ion-exclusion chromatography (EAIEC) is a new process concept with no known appearance in the litcrature. The basic feature of EAIEC is the use of air pressure or vacuum rather than water to remove the interstitial volume from the resin. With the EAIEC system the resin is always adsorbing 
hydrolyzate or releasing sugar and the resin is never in the presence of only water as it is in the batch feed column.

A conceptual design for a EAIEC system is shown in Figure 6. An operating cycle is started with the resin bed being saturated with hydrolyzate (step 1). After reaching equilibrium, the interstitial volume, which is now acid rich, is quickly removed by air pressure or vacuum, leaving an equilibrium amount of sugar trapped in the micropore volume of the bed (step 2).

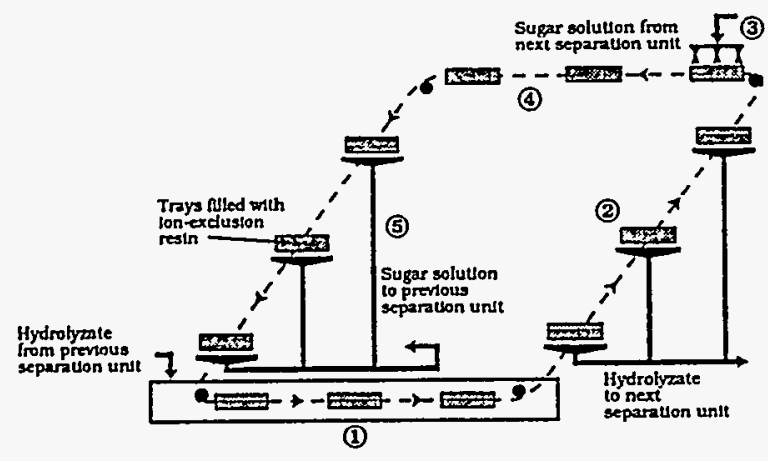

Figure 6. Possible EAIEC system

The resin bed is then saturated with rinse fluid such as water (step 3 ) and after equilibrium is reached (step 4), the resin bed is again purged of the interstitial volume, which now contains an equilibrium concentration of sugar, by air pressure or vacuum (step 5). The hydrolyzate used to saturate the resin may be the purged interstitial volume from another unit and the rinse fluid may be the sugar stream from another unit so that several of these units can be connected in series. In such an arrangement, the sugar stream would become more concentrated with each unit while the acid concentration of the hydrolyzate would decrease due to the addition of water to the system at each unit.

To estimate the performance of the EAIEC, a third mathematical model was developed. The model was derived by calculating mass and volume balances to obtain the equilibrium concentration of each species in each step of each unit in the process.
For mathematical purposes a single unit can be viewed as shown in Figure 7. The derivation leads to equations for determining the acid concentration and stream volumes for each unit. The concentration of acid is given by

$$
y_{H n}=-1+\frac{\sqrt{1+4 \beta k_{s} k_{I} Y_{H n_{-1}}}}{2 \beta k_{I} k_{B}}
$$

The volume of the hydrolyzate stream in unit $n$ is given by

$$
V_{H n}=V_{H n-1}+k_{r} \beta V_{H n-1}\left(1-S_{n}\right)
$$

where $S_{n}=1-k_{s} y_{H n}$ is the resin shrinkage factor. The volume of sugar in the sugar stream is given by

$$
V_{s_{n+1}}=V_{B_{n}}+V_{H_{n}}-V_{H_{n-1}}
$$

$\mathrm{V}_{\mathrm{s} 1}=\alpha \mathrm{k}_{\mathrm{r}} \mathrm{V}_{\mathrm{H} 0}$ and $\mathrm{V}_{\mathrm{H} 0}$ is the volume of hydrolyzate introduced to unit 1 .

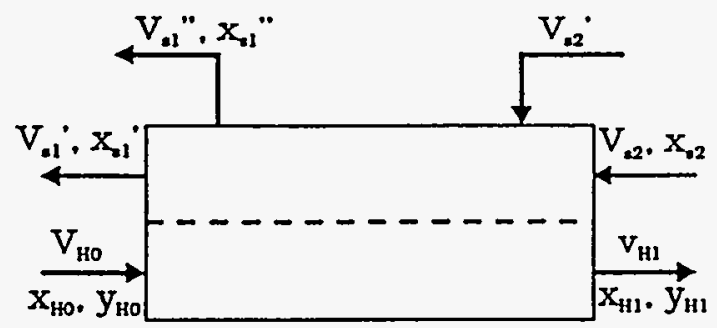

Unit 1

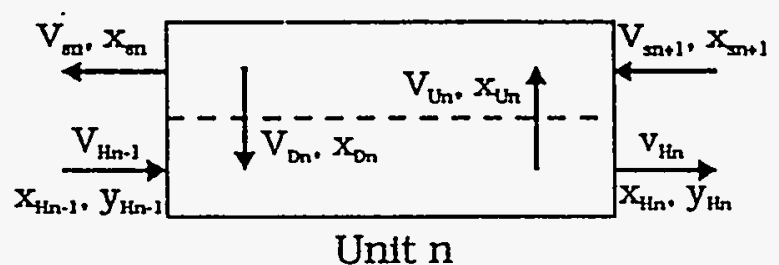

Figure 7. Mathematical conception of the EAIEC design 
Where:

$\mathrm{V}_{\mathrm{Hn}}=$ volume of hydrolyzate stream leaving unit $n$ and entering unit $n+1$,

$V_{3 n}=$ volume of sugar stream leaving unit $n$ and entering $n-1$,

$\mathrm{x}_{\mathrm{Hin}}=$ sugar concentration in hydrolyzate leaving unit $\mathrm{n}$,

$y_{H n}=$ acid concentration in hydrolyzate leaving unit $n$ and entering unit $n+1$,

$x_{3 n}=$ sugar concentration in sugar stream leaving unit $\mathrm{n}$ and entering unit $\mathrm{n}-\mathrm{l}$,

$\mathrm{V}_{\mathrm{si}}, \mathrm{x}_{\mathrm{si}} \mathrm{i}^{\mathrm{i}}=$ components of sugar stream leaving unit 1 after first wash,

$\mathrm{V}_{s 2^{\circ}}=$ volume of second wash on unit 1 ,

$\mathrm{V}_{\mathbf{s}}, \mathrm{x}_{\mathrm{s1}}{ }^{\prime \prime}=$ components of sugar stream leaving unit 1 after second wash,

$\mathrm{V}_{\mathrm{Dn}}, \mathrm{x}_{\mathrm{Dn}}=$ components of fluid in resin returned to hydrolyzate stream,

$\mathrm{V}_{U_{n}}, x_{U_{n}}=$ components of fluid in resin carried to sugar stream,

$\mathrm{k}_{\mathrm{r}}=1 /(\alpha+\beta)$

$\mathrm{k}_{\mathrm{s}}=$ resin shrinkage factor coefficient,

$\mathrm{K}_{\mathrm{s}}=$ distribution coefficient for sugar

The sugar concentrations for all units are given by a matrix equation of the form $\mathrm{MX}=\mathrm{C}$ where $M$ is the coefficient matrix, $X$ is the solution vector, and $\mathrm{C}$ is a constant vector. Calculations done with the model indicate that a five-unit system operating with a dual wash on the lead unit would result in a sugar recovery of $41.9 \%$. Since most of the sugar is recycled to the hydrolysis unit, an equilibrium sugar concentration will eventually be reached in the process. In a process such as the concentratedacid hydrolysis process, in which process temperatures never go beyond $100^{\circ} \mathrm{C}$ and sugar degradation is negligible, it may be possible to attain much higher sugar concentrations in the system.

Figure 8 shows a three-unit single water wash on the lead unit arrangement with a material balance.

\section{Economic Analysis}

Before the design and construction of the preparative-scale IEC unit was begun, an economic analysis was prepared to compare lime precipitation and IEC in the TVA concentratedacid hydrolysis process (Nanguneri 1989). The results of this analysis indicated that replacing the lime precipitation process with a batch feed IEC process could result in reduction in process costs of $45 \%$ or more.

To compare the batch feed IEC system to the continuous feed and EAIEC systems, it was decided to prepare a simplified cost estimate for the various processes. The estimates were based on processing $1000 \mathrm{lb} / \mathrm{hr}$ of cotton linters waste through a concentrated-acid hydrolysis unit. A summary of the results of the analysis are shown in Table 2.

Table 2. Comparison of IEC Processes

\begin{tabular}{|l|c|c|c|c|}
\hline System & $\begin{array}{l}\text { Batch } \\
\text { Feed }\end{array}$ & $\begin{array}{l}\text { Continuous } \\
\text { Feed }\end{array}$ & $\begin{array}{l}\text { EAIEC } \\
\mathrm{n}=3\end{array}$ & $\begin{array}{l}\text { EAIEC } \\
\mathrm{n}=5\end{array}$ \\
\hline $\begin{array}{l}\text { Resin } \\
\text { ft/hb sugar day }\end{array}$ & 0.76 & 0.09 & 008 & 0.11 \\
\hline $\begin{array}{l}\text { Water } \\
\text { lb water } / \mathrm{b} \text { sugar }\end{array}$ & 87 & 26 & 40 & 30 \\
\hline Relative Cost (\$) & 0.090 & 0.020 & 0.022 & 0.025 \\
\hline
\end{tabular}

The relative custs is based on the cost of evaporating the water used and replacing $20 \%$ of the resin each year. As can be seen, the relative cost for the three- and five-unit EAIEC processes are nearly the same. Based on current information, it can be assumed that the labor cost for the continuous feed IEC process and the EAIEC process would be approximately the same as that of the batch feed system.

\section{Conclusion}

Work conducted at The University of Southern Mississippi and TVA has demonstrated the potential of IEC as a candidate technology for separating acid and sugar in hydrolyzates. Problems originally encountered with dispersion in the preparative-scale IEC unit were solved permitting better predictions of IEC perform ance based on mathematical models. Based on a preliminary economic analysis, the cost for a continuous feed or EAIEC system operating with concentrated-acid hydrolysis unit procesing 1000 $\mathrm{lb} / \mathrm{h}$ of cotton linters waste to ethanol would be reasonable. 


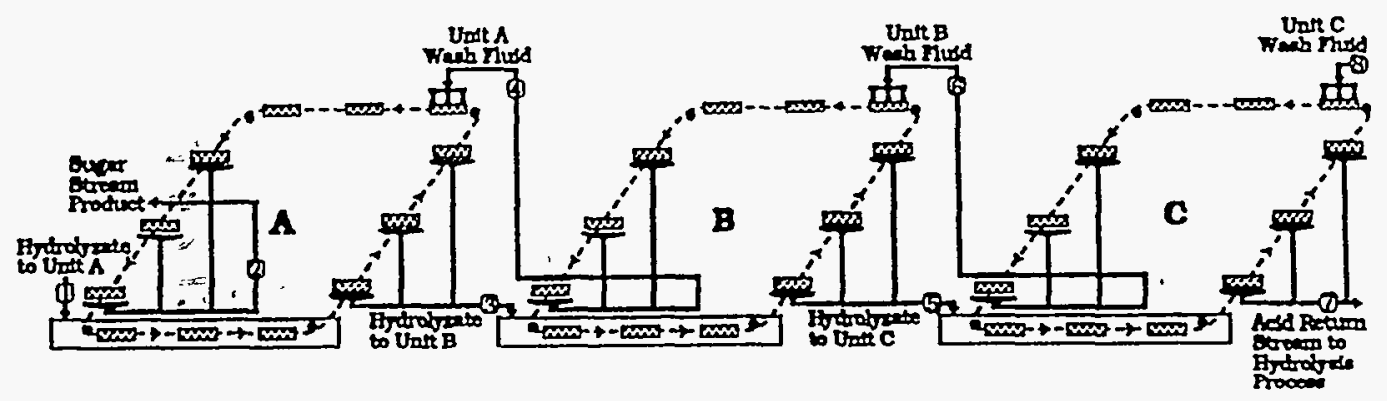

\begin{tabular}{|c|c|c|c|c|c|c|c|c|}
\hline Btromen I & 1 & 2 & $\mathbf{s}$ & 4 & 8 & 6 & 7 & 8 \\
\hline 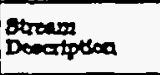 & Dredreate & Oxper vaream & $\begin{array}{l}\text { Ifdraberte } \\
\text { to unert B }\end{array}$ & UnttA nusd & Do untede & Untt: & 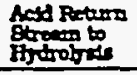 & Dot C \\
\hline 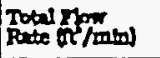 & 2.000 & 0.500 & 1.000 & 0.602 & 1.125 & 0.025 & 1.188 & 0.608 \\
\hline 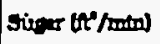 & 0.000 & 0.004 & 0.078 & 0.0000 & 0.000 & 0.013 & 0.006 & 0.000 \\
\hline Ned $\left(x^{2} / \mathrm{m}\right.$ & 0.150 & 0.000 & 0.180 & 0.000 & 0.180 & 0.000 & 0.180 & 0.000 \\
\hline | Water the $/ \mathrm{mm}$ ) & 0.770 & 0.178 & 0.886 & 0.812 & 0.008 & 0.612 & 0.008 & 0.688 \\
\hline
\end{tabular}

Figure 8. Three-unit EAIEC system and material balance

\section{References}

Farina, G. E., J. W. Barrier, and M. L. Forsythe. 1988. "Fuel Alcohol Production from Agricultural Lignocellulosic Feedstocks." Energy Sources, 10, 231-237.

King, C. J. 1980. Separation Processes. New York: McGraw-Hill.

Kunin, R. 1972. Ion Exchange Resings, 2nd ed. Robert E. Krieger: Huntington, KY.

Nanguneri, S. R. and R. D. Hester. 1990. "Acid/Sugar Separation Using Ion Exclusion Chromatography Resins: A Process Analysis and Design." Separation Science and Tech., 25 (13-15), 1829-42.

Nanguneri, S. R. 1991. "Design, Development and Analysis of a Preparative Scale Ion Exclusion Chromatography System." Ph.D. Dissertation. The University of Southern Mississippi. (Not currently available.)
Numan, R. P., S. R. Rudge, and M. R. Ladisch. 1987. "Sulfuric Acid-Sugar Separation by Ion Exclusion." Reactive Polymers, 5, 55-61.

Streat, M. 1980. "Recent Developments in Continuous Ion Exchange." J. Sep. Process. Technol., 1(3), 10.

Treybal, R. E. 1980. Mass Transfer Operations, 3rd ed. New York: McGraw-Hill.

Wankat, P. C. 1986. "Large Scale Adsorption and Chromatography." vol 2, CRC Press Inc: Boca Raton, Florida.

Wheaton, R. M. and W. C. Bauman. 1953. Ind. Eng. Chem., 45, 228.

Wheaton, R. M. and W. C. Bauman. 1953. Annuals of the New York Academy of Sciences, $57,159$. 